\title{
Dehydration of the stratosphere
}

\author{
M. R. Schoeberl ${ }^{1}$ and A. E. Dessler ${ }^{2}$ \\ ${ }^{1}$ Science and Technology Corporation, Lanham, MD, USA \\ ${ }^{2}$ Texas A\&M University, College Station, TX, USA
}

Received: 16 March 2011 - Published in Atmos. Chem. Phys. Discuss.: 29 March 2011

Revised: 1 August 2011 - Accepted: 2 August 2011 - Published: 18 August 2011

\begin{abstract}
Domain filling, forward trajectory calculations are used to examine the global dehydration processes that control stratospheric water vapor. As with most Lagrangian models of this type, water vapor is instantaneously removed from the parcel to keep the relative humidity $(\mathrm{RH})$ with respect to ice from exceeding saturation or a specified super-saturation value. We also test a simple parameterization of stratospheric convective moistening through ice lofting and the effect of gravity waves as a mechanism that can augment dehydration. Comparing diabatic and kinematic trajectories driven by the MERRA reanalysis, we find that, unlike the results from Liu et al. (2010), the additional transport due to the vertical velocity "noise" in the kinematic calculation creates too dry a stratosphere and a too diffuse a water-vapor tape recorder signal compared observations. We also show that the kinematically driven parcels are more likely to encounter the coldest tropopause temperatures than the diabatic trajectories. The diabatic simulations produce stratospheric water vapor mixing ratios close to that observed by Aura's Microwave Limb Sounder and are consistent with the MERRA tropical tropopause temperature biases. Convective moistening, which will increase stratospheric HDO, also increases stratospheric water vapor while the addition of parameterized gravity waves does the opposite. We find that while the Tropical West Pacific is the dominant dehydration location, but dehydration over Tropical South America is also important. Antarctica makes a small contribution to the overall stratospheric water vapor budget as well by releasing very dry air into the Southern Hemisphere stratosphere following the break up of the winter vortex.
\end{abstract}

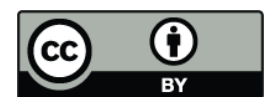

Correspondence to: M. R. Schoeberl (mark.schoeberl@mac.com)

\section{Introduction}

The precise mechanism that controls stratospheric water vapor has been studied for more than $60 \mathrm{yr}$ - since the publication of Brewer's seminal paper (Brewer, 1949). Over that time, significant progress has been made and many of the details of how air is dehydrated as it enters the stratosphere are now understood. For example, we know that most stratospheric dehydration takes place in a region called the tropical tropopause layer (TTL) (Sherwood and Dessler, 2000; Fueglistaler et al., 2009), a region in the tropics between the 355 and $400 \mathrm{~K}$ potential temperature surfaces, corresponding to altitudes between about 15 and $18 \mathrm{~km}$.

Lagrangian back-trajectory calculations are one of the important tools used to understand this issue. These calculations use analyzed winds and large-scale temperatures and are able to accurately reproduce many of the details of TTL dehydration process and lower stratospheric water vapor (e.g., Fueglistaler et al., 2005; Jensen and Pfister, 2004; Gettelman et al., 2002). These simple calculations demonstrate that the zeroth-order physics governing the water vapor abundance in the TTL appears to be temperature variations along the advective path air parcels take as they move into the lower stratosphere (e.g., Mote et al., 1996; Fueglistaler et al., 2009; Liu et al., 2010).

The typical set-up for back trajectory calculations begins with a grid of parcels in the lower stratosphere that are subsequently advected backwards for a few months. Those parcels that reach the upper troposphere are then analyzed with regard to origin and temperature history and the location of the Lagrangian Dry Point (LDP) (e.g. Liu et al., 2010), the point where the final stratospheric water vapor mixing ratio is established. (In this paper we refer to the LDP as the final dehydration point.) As is clear from age-of-air measurements, a significant number of parcels in the lower tropical stratosphere may not be traceable back to the upper troposphere after a few months of back trajectory integration. For example,

Published by Copernicus Publications on behalf of the European Geosciences Union. 
some parcels have their final dehydration point within the Antarctic vortex where the mean age of air is $4-5 \mathrm{yr}$. In principle, very long back trajectory calculations could provide all the information on dehydration processes needed to understand stratospheric observations, but long back trajectory runs would have to be initialized for each day of the year, for example, to provide a complete picture stratospheric dehydration.

An alternative to the back trajectory approach is to use domain filling forward trajectories. By domain filling we mean continuously releasing parcels near the tropopause so that hundreds of thousands of parcels eventually fill the stratosphere and provide a statistically robust population for analysis. This approach provides a continuous picture of the time evolution of stratospheric constituents allowing us to investigate issues that are difficult to address with that traditional back-trajectory approach or with Eulerian chemical-transport models.

Previous trajectory calculations have often neglected at least three important processes relevant to the control of stratospheric water vapor. First, dehydration is usually set to occur at $100 \% \mathrm{RH}$, meaning that super-saturation is not included in the analyses. Observations, however, show ice super-saturation is commonly observed in the tropics (Jensen et al., 2005). Second, temperature fluctuations not resolved by the reanalysis (e.g. from gravity waves) are not included except, unintentionally, through noise in the analysis. As shown by Jensen and Pfister (2004), these fluctuations are important for accurately reproducing TTL temperatures. And, third, ice lofting by convection is neglected. Observations show that convection does indeed reach up to and beyond the tropopause (Alcala and Dessler, 2002; Zipser et al., 2006; Dessler et al., 2006), and convection brings up iceladen air from the boundary layer that can evaporate moistening the lower stratosphere. Previous analyses have demonstrated that convective ice lofting can explain the observed enriched abundance of HDO in the TTL and lower stratosphere (Moyer et al., 1996; Keith, 2000; Dessler et al., 2007).

Another issue is the mode of transport. In trajectory models, the vertical transport can be either diabatic or kinematic. Danielson (1961) pioneered the use of diabatic vertical transport to remove the adiabatic noise generated by the model. Schoeberl et al. (2003) noted the impact on the transport and age-of-air between diabatic and kinematic trajectory calculations. More recently Ploeger et al. (2010) performed a series of tropical back trajectory experiments noting that the kinematic and diabatic trajectories produce significantly different residence times in the TTL. Liu et al. (2010) performed an extensive study of stratospheric dehydration using domain filling back trajectory calculations comparing both diabatic and kinematic trajectory schemes and found that the choice of trajectory transport scheme had significant impact on the water vapor field as will be discussed further below.

The main work discussed here is a domain filling forward trajectory analysis directed toward simulating the water va- por content of the stratosphere. In the next section we describe the model including the parameterizations for gravity waves, dehydration, convective moistening and methane photolysis. In Sect. 3 we describe our results. Summary and conclusions are presented in Sect. 4.

\section{Model}

\subsection{Dynamics}

All of our experiments use the Modern Era RetrospectiveAnalysis for Research and Applications (MERRA) (Bosilovich et al., 2008; Rienecker et al., 2011) for winds and temperatures. The MERRA assimilated data set runs from 1979 to the present and uses the GEOS-5 assimilation system. MERRA spatial resolution is $1 / 3 \mathrm{deg}$. longitude by $0.5 \mathrm{deg}$. latitude, although the wind, omega, and heating rate data (the sum of radiative and latent heat) we are using has been averaged down to $1.25^{\circ}$ by $1.25^{\circ}$. The MERRA model has 72 pressure levels extending from the surface to $0.1 \mathrm{hPa}$, but these fields are reported on 42 levels. In the TTL and lower stratosphere, the winds are available at $150,100,70$, and $50 \mathrm{hPa}$.

Because of the importance of temperature in our analyses, we use the MERRA's full resolution (both in the horizontal and vertical) temperature field. This vertical resolution is about $\sim 1 \mathrm{~km}$ in the TTL and lower stratosphere. Between MERRA levels we linearly interpolate temperatures from the MERRA pressures to parcel locations. For the diabatic calculations, where the vertical coordinate is potential temperature, we interpolate MERRA temperatures to a potential temperature grid. This grid has 64 unequally spaced levels from $330-1800 \mathrm{~K}$. There are 40 levels between 360 and $440 \mathrm{~K}$ to minimize any interpolation bias in the UTLS. Finally, all data used here are daily average fields rather than the 6-hourly data; this is done to make the meteorological data set a more manageable size.

Water vapor is controlled mostly by ice saturation at the tropical tropopause. For example, at $100 \mathrm{hPa}$, a temperature change from $194 \mathrm{~K}$ to $190 \mathrm{~K}$ will change the ice saturation value from water vapor mixing ratio from 6.2 to 3.2 ppmv. Thus any temperature bias can result in a significant stratospheric water vapor bias. MERRA January tropical tropopause temperatures are on the average 1.2$2 \mathrm{~K}$ warmer than ERA Interim temperatures (S. Pawson, private communication, 2011). We have found that MERRA is on the average about $\sim 0.3 \mathrm{~K}$ colder than $100 \mathrm{hPa}$ Singapore sonde measurements between 1980-2009. The MERRA validation tropical sonde data set (S. Pawson) shows about the same cold bias for the 2005-2009 January periods. Given these observational biases, we expect that our simulations will be somewhat dry compared to observations for ice saturation levels set to $100 \%$. 
We use the Bowman trajectory code (Bowman, 1993; Bowman and Carrie, 2002) that can run in either diabatic or kinematic mode. This code is significantly faster than the Goddard Trajectory Model (Schoeberl and Sparling, 1995) allowing the longer trajectories required by this approach. Temperatures are linearly time-space interpolated onto parcel positions. Parcel positions are output every $45 \mathrm{~min}$ along the trajectory and temperatures are interpolated to the parcel position at each step. Running with $\sim 500000$ parcels, the Bowman code can perform a 25 -yr forward calculation in 4-5 days on a quad-core Unix workstation. This speed allows us to perform multiple experiments on the sensitivity of stratospheric water vapor to transport scheme, the level of super-saturation, as well as the impact of gravity waves and convective moistening.

We have performed both kinematic and diabatic trajectory calculations similar to Schoeberl et al. (2003), Ploger et al. (2010) and Liu et al. (2010). As mentioned above, kinematic means that the vertical coordinate is pressure and the parcels are moved using the MERRA's pressure tendency (omega) field whereas diabatic means that the model operates in isentropic coordinates and uses the net diabatic heating to move parcels across PT surfaces.

The model integration begins with the insertion of a parcels arranged on a longitude-latitude grid (typically $\left.5^{\circ} \times 2^{\circ}\right)$ at $250 \mathrm{hPa}(\sim 10 \mathrm{~km})$ for the kinematic runs or at $360 \mathrm{~K}$ for the diabatic runs. The parcel grid extends from $\pm 60^{\circ}$ latitude and covers all longitudes. The insertion potential temperature is chosen such that it is, on average, above the level of zero net radiative heating - roughly the base of the TTL (Gettelman and Forster, 2002; Fueglistaler et al., 2009). A new parcel grid is added to the model's parcel field each day approximating a continuous injection. Both the kinematic and diabatic models remove parcels at the end of each day if the parcel pressure is $250 \mathrm{hPa}$ or higher. The assumption in this removal scheme is that these parcels have re-entered the troposphere. We tested this assumption by increasing removal pressure to $300 \mathrm{hPa}$ to see how it affected our statistics and found that although more parcels accumulated in the lower portion of the domain, the statistics and water vapor field for the stratosphere was only very slightly affected. The very few parcels ascending above $1800 \mathrm{~K}$ in the diabatic model or reaching pressures below $0.2 \mathrm{hPa}$ in the kinematic model are also removed. The spatial density of the parcel injection grid controls the total number of parcels in the stratosphere. With the spatial density described above the model reaches steady-state of about $\sim 500000$ parcels. This number ensures that we will have enough parcels in the stratosphere for a statistically robust quantitative analysis.

In each case reported here, the model is started 1 January 2000 and integrated to the end of 2009. For the first two to three years, the number of parcels in the stratosphere grows. After that, the total number stabilizes. Thus we can safely compare the model results starting in 2005 with Aura MLS water vapor data.

\subsection{Water vapor and dehydration}

All injecton grid parcels are initiated with $200 \mathrm{ppmv}$ water vapor, the approximate value of water vapor at $250 \mathrm{hPa}$ in the tropics. The Marti and Mausberger (1993) (M\&M) relation is used to calculate the saturation vapor pressure with respect to ice. A recent review by Murphy and Koop (2005) suggest that M\&M results are about $2 \%$ too high at tropical tropopause pressures and temperatures - too small a difference to be important for this study. When the RH exceeds a pre-determined threshold, enough water is removed from the parcel to reduce the RH to $100 \%$. In most previous Lagrangian studies, the removal threshold has been set at exactly $100 \% \mathrm{RH}$; however, frequent observations of supersaturation in the TTL (Jensen et al., 2005) suggest that the actual threshold might be higher and allowing the threshold to exceed $100 \% \mathrm{RH}$. Varying the saturation RH allows us to test the importance of super-saturation. We do not consider re-evaporation of the condensate in the studies shown here although Liu et al. (2010) argue that the low bias in water vapor seen in their back trajectory studies could be due to neglect of the re-evaporating condensate.

\subsection{Convective moistening}

As mentioned above, the observed abundance of stratospheric HDO (Moyer et al, 1996; Keith et al., 2000; Johnson et al., 2001; Hanisco, et al., 2007, Steinwagner et al., 2010) exceeds the amount predicted by Rayleigh fractionation, a theoretical limit derived by assuming that HDO-rich condensate formation and removal occurs at $100 \%$ RH. One explanation for the larger than expected stratospheric HDO abundance is the direct injection and evaporation of HDOrich ice into the stratosphere through convective lofting. As shown by Dessler et al. (2007) a small amount of the convective lofting of HDO-rich ice can significantly increase the HDO concentration in the stratosphere. While we do not include HDO in our model, we do assess the effect of convective moistening on the stratospheric water vapor budget.

To simulate the convective moistening process, we use the scheme developed by Dessler et al. (2007). To determine when and where trajectories are influenced by convection, we first derive a spatial probability of convective influence as a function of pressure and the flux of outgoing longwave radiation (OLR) (Liebmann and Smith, 1996). We then use measurements of height-resolved ice-water content (IWC) from the Aura Microwave Limb Sounder (MLS) (Livesey et al., 2005) to determine vertical distribution of the probability. Unlike Dessler et al. (2007), our probability table is a function of latitude and month, and is built from data obtained from OLR and IWC covering 2004-2010.

At specific intervals along each trajectory, we use the probability table and the parcel's pressure and collocated OLR to determine a probability for convective influence. A random number generator is then used to determine whether the 
trajectory is actually influenced by convection at that time. For pressure $<68 \mathrm{hPa}$, the probability is zero; for pressure $>146 \mathrm{hPa}$, we use the 146-hPa probability.

When convection impacts a parcel, we set the parcel's RH to $100 \%$. This means that sub-saturated parcels are hydrated and super-saturated parcels are dehydrated by convection (Jensen et al., 2007). There are two adjustable parameters in this model, the frequency at which we test for convection and the maximum detrainment level. Increasing the testing frequency increases the probability that a parcel will be impacted by convection. For the experiments shown here we test for convection once a day. Parcels that are above the maximum detrainment level are never moistened so increasing the height of the maximum detrainment level will moisten parcels that may have already been dehydrated at colder temperatures and thus will increase the water vapor in the stratosphere. The convective moistening parameterization is only implemented for the diabatic calculation. The detrainment level is set to $375 \mathrm{~K}$.

\subsection{Gravity waves}

Gravity waves can produce adiabatic temperature excursions that are unresolved by the MERRA anaysis, and these temperature excursions can produce condensation and additional dehydration. Jensen and Pfister (2004) modeled the effect of gravity waves and showed that they had the potential to reduce stratospheric water vapor by $\sim 0.5 \mathrm{ppmv}$ or so. In the tropics, both high frequency inertial gravity waves and low frequency Kelvin and mixed Rossby gravity waves are present. Outside the tropics only the high frequency waves are common. In order to parameterize gravity wave effects we approximate the temperature amplitudes and frequencies from Table 1 of Jensen and Pfister (2004). We only use the inertial gravity wave fields since the Kelvin and Mixed Rossby-Gravity wave fields are present in the analysis. We assume that the gravity wave temperature fluctuations $(\mathrm{K})$ are given by:

$T_{\mathrm{g}}=M\left(0.8 \sin \left(\omega_{\mathrm{h}} t+\phi_{\mathrm{h}}\right)\right) \mid$ latitude $\mid<15^{\circ}$

$T_{\mathrm{g}}=M\left(0.5 \sin \left(\omega_{\mathrm{h}} t+\phi_{\mathrm{h}}\right)\right) \mid$ latitude $\mid>15^{\circ}$

where $M$ is an arbitrary tuning factor $(M=1.0$ approximates the Jensen and Pfister (2004) simulation). We set $\omega_{\mathrm{h}}=1.1 \times 10^{-4} \mathrm{~s}^{-1}$ to simulate high frequency waves. The phase, $\phi$, is a uniformly distributed random number between 0 and $2 \pi$. This scheme reduces stratospheric water vapor by $\sim 0.2 \mathrm{ppmv}$ for $M=1$.

\subsection{Stratospheric water sources}

Oxidation of hydrogen-containing species, primarily methane, is an important in situ source of water in the stratosphere (Wofsy et al., 1972; Le Texier et al., 1988). To account for methane oxidation, we independently track methane in each parcel and photolyze it using photochemical loss rates supplied from the Goddard two-dimensional model (Fleming, et al., 2007). Loss of each molecule of methane produces two molecules of $\mathrm{H}_{2} \mathrm{O}$ (Dessler et al., 1994). The oxidation of $\mathrm{H}_{2}$ formed from methane photolysis is implicitly included in this scheme. Methane concentration is set at $1.8 \mathrm{ppmv}$ for all injected parcels.

\section{Results}

Table 1 gives an overview of the numerical experiments performed. All of the results are for the last few days of our 10-yr integrations unless indicated otherwise. In these runs, we vary the amount of super-saturation, the presence of convective moistening (CM), gravity waves (GW) and the transport scheme ( $K$ for kinematic or $D$ for diabatic). We compare our results to the global average Microwave Limb Sounder (MLS) water vapor from 18-28 km for the same day (Lambert et al., 2007; Read et al., 2007). We use MLS version 3.3 data, which is an improvement over the validated Version 2 data (see http://mls.jpl.nasa.gov/data/ v3-3_data_quality_document.pdf) The MLS limb water vapor measurements have $2-3 \mathrm{~km}$ vertical resolution. We note that the reported accuracy of MLS water vapor at lower stratospheric levels is $5-7 \%$ or about 0.3 ppmv.

As might be expected from the MERRA cold temperature bias, the D100 water vapor concentration is below the MLS observations. Super-saturation increases stratospheric water vapor by reducing the occurrence of dehydration events. Convective moistening also increases water vapor in the stratosphere by rehydrating parcels that have already experienced their final dehydration. The gravity wave parameterization reduces the water vapor through excursions to lower temperatures. The best agreement with MLS is achieved, including reasonable simulation of the tropical tape recorder (see below), with $104 \%$ super-saturation using diabatic simulation, no gravity waves and no convective moistening. However, if we believe that convective moistening is required then we need to include gravity waves to correct for the excessive moisture. Since the MLS observations are only accurate to about 5-7\% we cannot be completely quantitative on the level of convective moistening and gravity wave dehydration required to reproduce the stratospheric water vapor fields. One important conclusion is that there are several ways to match the observations, and one challenge for the future is to find ways to constrain the system further.

\subsection{Parcel distribution}

Figure 1 shows the distribution of parcels at the end of the 10 -yr diabatic integration (uniformly thinned out by a factor of 10) overlaid on the zonal mean temperature field. As is usual with this kind of trajectory calculation, the parcel density decreases with altitude roughly in proportion to the 
Table 1. Summary of trajectory experiments.

\begin{tabular}{|c|c|c|c|}
\hline Experiment & Saturation & $\mathrm{H}_{2} \mathrm{O}^{*}$ & Comment \\
\hline K100 & $100 \%$ & 3.9 & $\begin{array}{l}\text { Too dry, tape recorder (TR) disperses } \\
\text { too fast with altitude }\end{array}$ \\
\hline K120 & $120 \%$ & 4.2 & $\begin{array}{l}\text { Slightly dry, TR disperses too fast } \\
\text { with altitude (Fig. 7) }\end{array}$ \\
\hline D100 & $100 \%$ & 4.4 & $\begin{array}{l}\text { Agrees with MLS, TR is coherent but phase lags } \\
\text { observations (true for all } D \text { experiments) }\end{array}$ \\
\hline D104 & $104 \%$ & 4.5 & Agrees with MLS \\
\hline D100GW & $100 \%+$ gravity waves & 4.2 & Slightly dry \\
\hline D100CM & $100 \%+$ convective moistening & 5.1 & Too wet \\
\hline $\mathrm{D} 100+\mathrm{CM}+\mathrm{GW}$ & $100 \%+$ gravity waves + convective moistening & 4.8 & Slightly wet \\
\hline $\mathrm{D} 100+\mathrm{CM}+1.5 \cdot \mathrm{GW}$ & $100 \%-1.5 \cdot \mathrm{GW} \& \mathrm{CM}$ & 4.6 & Agrees with MLS \\
\hline
\end{tabular}

* Global average between 18 and $28 \mathrm{~km}, \mathrm{MLS}=4.5 \pm 0.3 \mathrm{ppmv}(\sim 5-7 \%$ accuracy) for the same region.

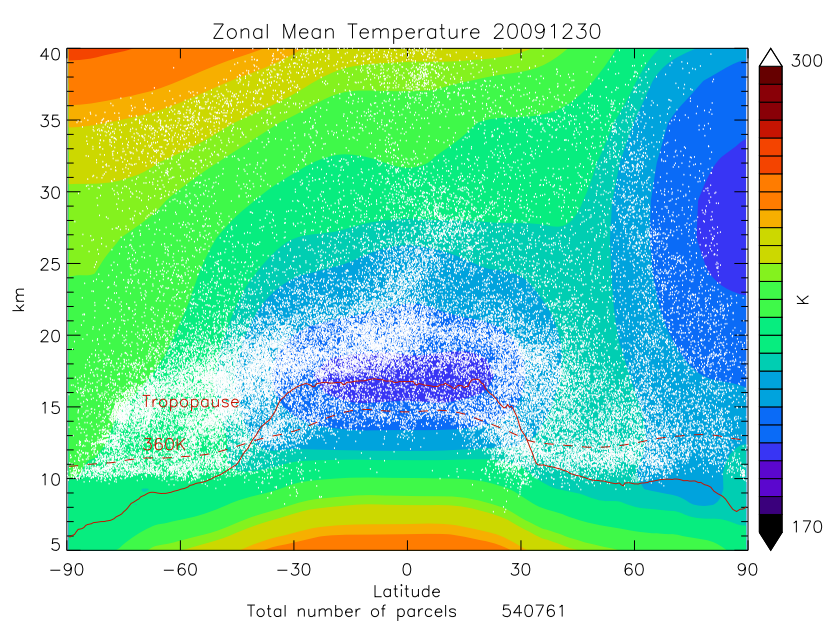

Fig. 1. Parcel distribution for diabatic experiment on 30 December 2009 thinned by a factor of 10 for visibility. Injection began 1 January 2000. Colors show the zonal mean temperature distribution from MERRA. Red lines identify the zonal mean $360 \mathrm{~K}$ and tropopause levels. Parcels moving below about $10 \mathrm{~km}$ are eliminated.

atmospheric density. The parcels tend to cluster at lower altitudes where the heating rates and vertical velocities are smaller. We also note that there is a relative paucity of parcels at the high northern latitudes above about $25 \mathrm{~km}$. This is the region of strong descent inside the vortex and parcels that originated at high altitudes are advected to lower altitudes. This effect is seen in the Southern Hemisphere six months earlier (not shown). We also note a thicker cluster of tropical parcels between 22 and $27 \mathrm{~km}$. This corresponds to the "the tropical pipe" region, where exchange with mid-latitudes is slow (Plumb, 2002). This isolation of the tropical region causes parcels to accumulate.

\subsection{Kinematic vs. diabatic trajectories}

The diabatic and kinematic computations give quite different water vapor results (Table 1). In theory, the model results should be independent of the transport scheme used, but as Danielson (1961) first noted, the aliasing of adiabatic gravity waves and numerical errors in the dynamical model create "noise" in the vertical velocity field and thus excessive parcel dispersion in kinematic trajectory calculations. This artificial dispersion significantly alters the age spectrum and transport properties determined by trajectory calculations (Schoeberl et al., 2003). The MERRA omega fields are time smoothed to reduce the model noise, but the noise is not entirely eliminated (see Fig. 7). The alternative to the kinematic models are the diabatic models that operate in potential temperature (PT) coordinates using the net heating rate to move parcels across PT surfaces. Kinematic parcel models tend to be much more dispersive than diabatic models when compared to observations, as seen by Liu et al. (2010) and other authors.

In our model, the spurious vertical motion provides extra opportunities for dehydration compared with the diabatic calculation (in which parcels move vertically through net heating). With extra opportunities to encounter cold temperatures, the stratospheric humidity computed by the kinematic model is low biased. In contrast, Liu et al. (2010) found that kinematic trajectories produce a much wetter stratosphere using ERA40. Among the reasons for their results, Liu et al. (2010) noted that the rapid dispersion of the kinematically transported parcels allowed the parcels to "avoid" the coldest tropopause. That is, they could cross into the tropical upper stratosphere in warmer tropical tropopuase regions, avoiding the West Pacific where the tropopause is coldest. In contrast, we find that our kinematically transported parcels actually have a higher probability of finding the cold point compared to the diabatic trajectories thus producing relatively lower stratospheric water vapor concentrations. Figure 2 shows an analysis that compares the final dehydration altitudes for the 


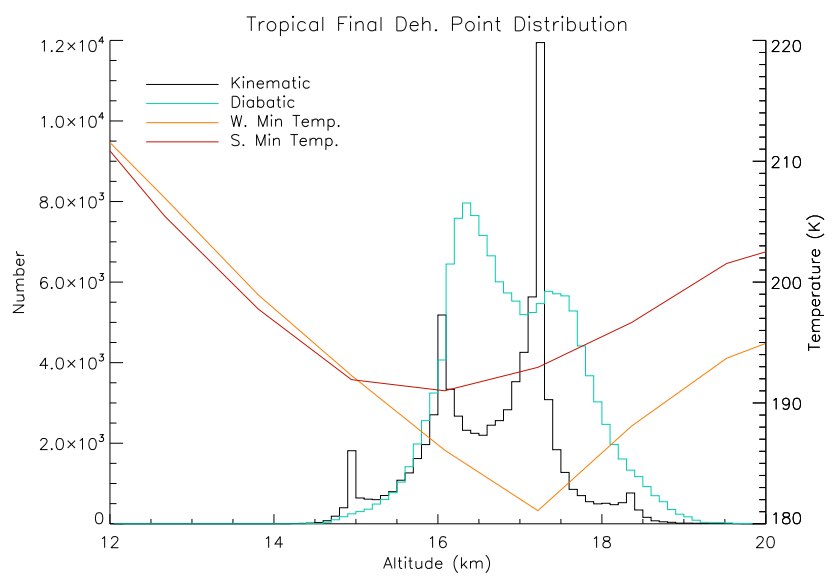

Fig. 2. Final dehydration location distribution vs. altitude for parcels that dehydrated $\pm 10^{\circ}$ from the equator. Overlaid are the tropical winter and summer and minimum temperature profiles (W. Min. Temp., S. Min. Temp.) for the same region from MERRA. The diabatic parcels dehydrate at warmer temperatures than the kinematic explaining the dry bias of the kinematic simulation.

diabatic and kinematic calculations along with the overlaid tropical minimum temperature profiles for winter and summer. Since we use linear interpolation of temperature in the vertical, the cold point will coincide with one of the MERRA levels so the dehydration points will tend to cluster at the levels $(\sim 16.1,17.2,18.4$, and $19.5 \mathrm{~km})$ around the tropopause. Figure 2 shows that in our model kinematic trajectories are much more likely to see the coldest point than are diabatic trajectories hence the relative drier stratosphere.

Our results and those of Liu et al. (2010) may not be in conflict. The time smoothing of the MERRA vertical velocity fields produces less transport dispersion than the untime-smoothed fields ERA40 fields used by Liu et al. (2010) If vertical dispersion is very high, as would be the case with unsmoothed velocity fields from ERA40, parcels could reach the stratosphere avoiding the coldest temperatures. On the other hand, moderate levels of vertical dispersion from the time smoothed MERRA omega fields would allow tropical parcels at the edges of the coldest regions to disperse into the colder zones creating a low water vapor bias. Without more rigorous experiments we cannot explore this hypothesis further, and it is beyond the scope of this study.

Another way to compare the differences between the kinematic and diabatic models is to examine the age-of-air. Figure 3 shows the mean age for the diabatic and kinematic computations. The tropical pipe in the kinematic run is much narrower and young air extends only to about $\sim 24 \mathrm{~km}$ vs. $\sim 29 \mathrm{~km}$ in the diabatic case. Thus the "pipe" is more isolated in the diabatic experiment compared to the kinematic case. We also note that the zone of tropical young air is narrower in the kinematic calculation consistent with more meridional dispersion as suggested above.
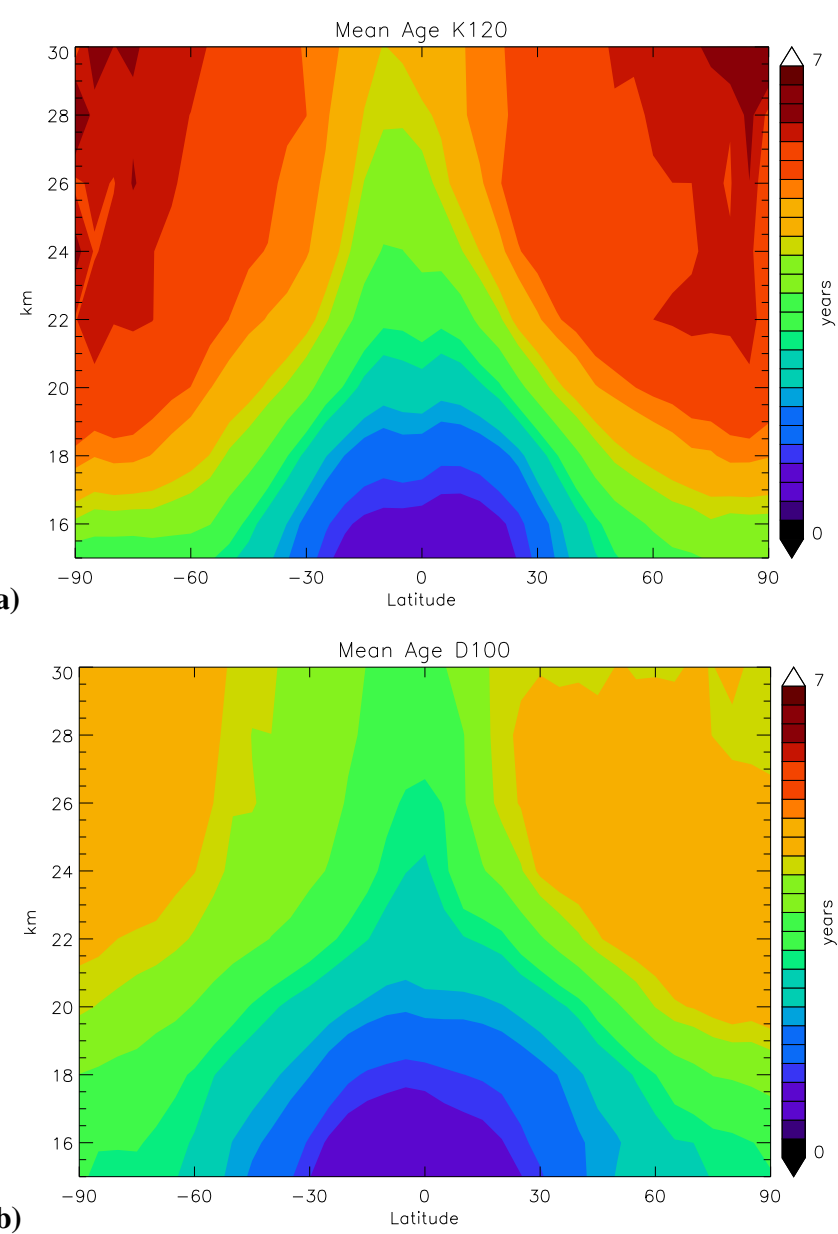

Fig. 3. (a) mean age for a kinematic trajectory run. (b) mean age for a diabatic trajectory run.

Figure 4 shows the comparison at $20 \mathrm{~km}$ with age estimates from $\mathrm{CO}_{2}$ and $\mathrm{SF}_{6}$ from Waugh and Hall (2002). In both the kinematic and diabatic case the air is too old in the tropics, which suggests that heating in both data sets is too weak near the tropopause. This is consistent with analysis by Schoeberl et al. (2008b) that showed that the vertical velocity in the GEOS- 4 assimilation was too weak at $20 \mathrm{~km}$ by almost a factor of two compared to vertical motion fields derived from the observed water vapor tape recorder signal. If the tropical vertical motion were stronger, then the age-of-air in the tropics would be younger and in better agreement with observations.

Outside the tropics, the kinematic model age for the extratropical lower stratospheric is too old ( 6 yr vs. $\sim 4$ years observed). This means that parcels reaching the upper stratosphere in the kinematic model have a much longer residence time than parcels in the diabatic model. As Fig. 3 implies, the lack of isolation of the tropics allows parcels to recirculate in and out of the tropical upper stratosphere increasing their age. 


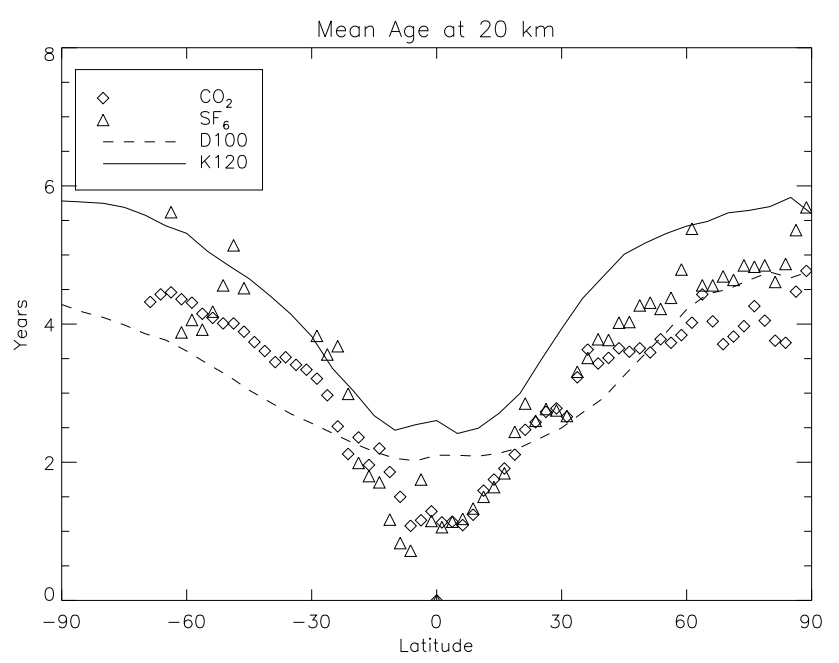

Fig. 4. Mean age averaged over a 2009 at $20 \mathrm{~km}$ with measurements based on $\mathrm{CO}_{2}$ and $\mathrm{SF}_{6}$ from Waugh and Hall (2002). Solid line, kinematic integration; dashed line, diabatic integration.

\section{Water vapor}

Given the kinematic trajectory transport biases we will now restrict our discussion to the diabatic integrations. Figure 5 shows the D100 simulations of water and the MLS zonal mean water vapor for the same day. Overall the agreement is within MLS measurement uncertainties, although the water vapor mixing ratio in D100 is slightly lower than MLS values. Liu et al. (2010) also found that the diabatic calculation was dry compared to observations, but much more so that our results. In Liu et al. (2010) the dry bias could be offset by a simple temperature increase of at the LDP. Both their result and ours highlight the importance of assimilated tropical tropopause temperature in determining the water vapor.

Figure 5 shows that both the tropical and Antarctic dry zones are well simulated. We also note that the model patch of tropical dry air at about $22 \mathrm{~km}$ is located at a somewhat lower altitude than in the MLS observations. This dry patch is a section of the tape recorder; the previous Northern Hemisphere $(\mathrm{NH})$ winter's dry TTL air that has ascended to $22 \mathrm{~km}$. The altitude offset between the model and MLS confirms that MERRA heating rates in the tropical lower stratosphere are slightly too low.

Figure 6 shows comparisons of monthly mean water vapor maps for January and August for the D100 experiment at $82 \mathrm{hPa}(\sim 17.5 \mathrm{~km})$ with MLS observations. There is overall excellent agreement between the model and the observed water vapor fields. We do note some important differences, though. The tropical west Pacific region is somewhat dryer than MLS observations and slightly wetter outside the tropics. On the other hand, the model has reproduced the dehydration region over South America consistent with the findings of Schiller et al. (2008). As we will show below, this is
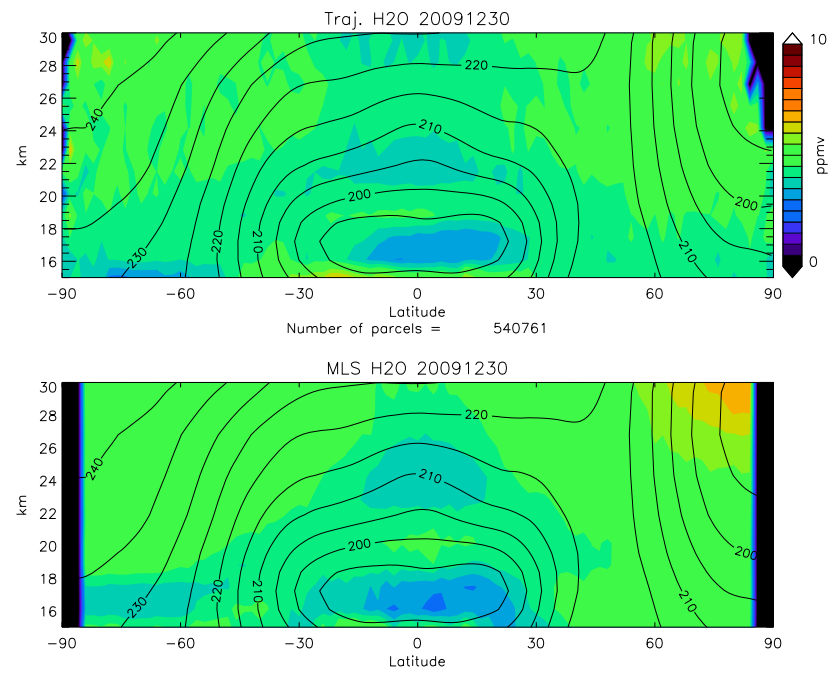

Fig. 5. Zonal mean water vapor mixing ratio at the end of the particle integrations - 30 December 2009 . Top D100 (Diabatic, $100 \%$ super-saturation) experiment, bottom MLS V3 observations (see Table 1). Zonal mean temperatures are shown as black contours. Temperature data are from MERRA.

an important region of $\mathrm{NH}$ winter dehydration.

For NH summer, the model reproduces the increase in tropical water vapor. Not only are there increases in water over the East Asia but over Central America as well. Outside the tropics the model reproduces the strong isolation of the Antarctic vortex and dehydration within the vortex domain (see Fig. 8 below). On the other hand, the model fails to reproduce the observed Arctic water vapor winter increase relative to mid-latitudes. Both methane and water show that the model fails to maintain a gradient across the Arctic boundary, suggesting too much cross-vortex mixing in MERRA.

Figure 7 shows the water vapor tape recorder (Mote et al., 1996; Schoeberl et al., 2008a and references therein) for D100, MLS and K120. The K120 simulation (Fig. 7a) shows rapid dispersal of the tape signal above $\sim 20 \mathrm{~km}$ compared to MLS (Fig. 7b). D100, Fig. 7c, on the other hand, shows a coherent tape signal through the lower stratosphere although, as mentioned above, the signal is ascending too slowly. The incoherence of the K120 tape signal is consistent with the mean age plots shown in Fig. 3 where we noted that penetration of old air into the tropics from mid-latitudes would increase the age and narrow the tropical pipe. We also note that the upward moving water vapor (Fig. 7b, c) anomalies show downward bends in 2006 and 2008 near $20 \mathrm{~km}$. This is the effect of the descending QBO circulation on the anomaly field, which is well reproduced in the MERRA heating rate data. 


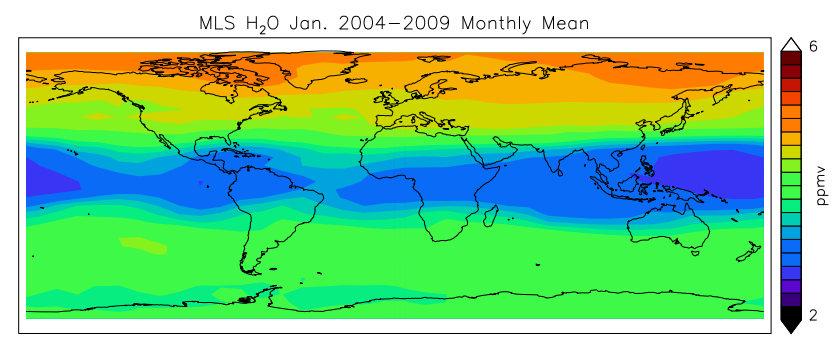

(a)
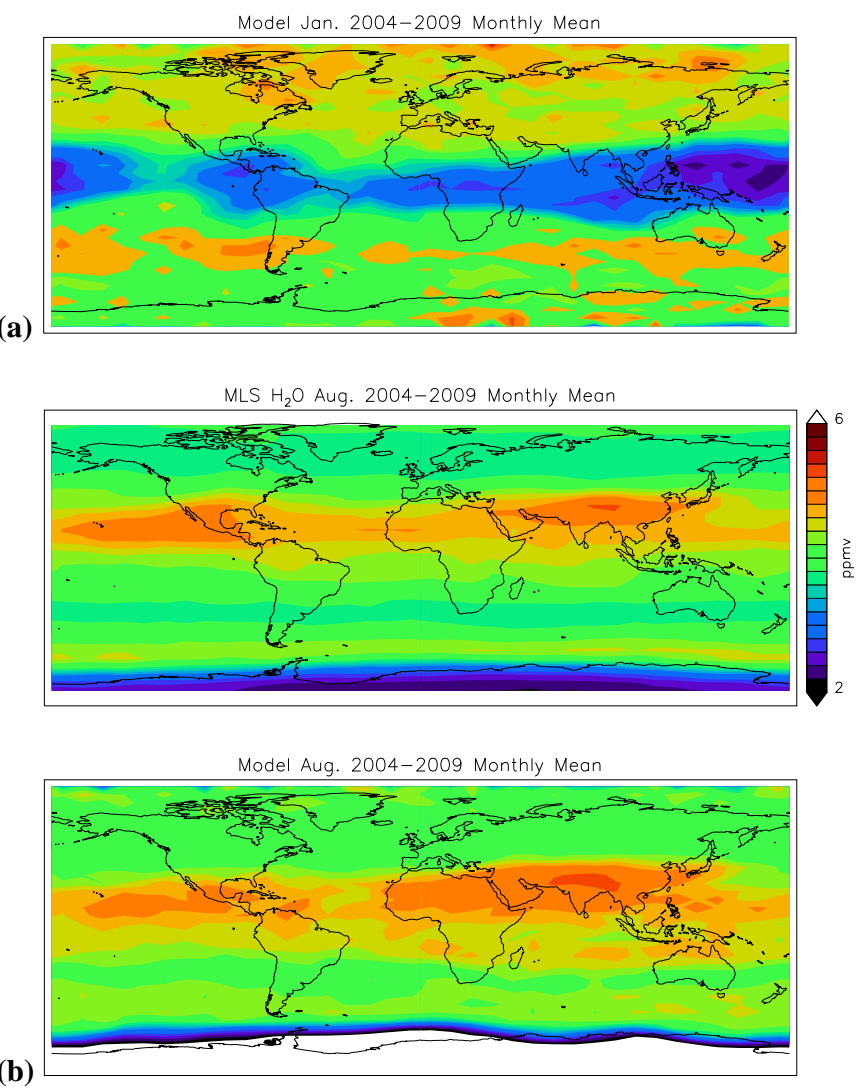

Fig. 6. Monthly mean water vapor at $82 \mathrm{hPa}(\sim 17.5 \mathrm{~km})$ for January (a) and August 2005-2009 (b) for the model and MLS; D100 experiment.

\subsection{Location of final dehydration events}

Parcels moving through the TTL and lower stratosphere can dehydrate multiple times. Thus the most relevant statistic is the location of final dehydration point because this is what ultimately determines the stratospheric water vapor concentration. We find that multiple dehydration events within a month or so after parcel release with the parcels experiencing fewer dehydration events afterwards . Thus to provide a pattern of final dehydration we select parcels that are older than a year because a few of these parcels will subsequently dehydrate further.

In Fig. 8 we show statistics of the locations of final dehydration point density for all D100 parcels. For all the di- (a)

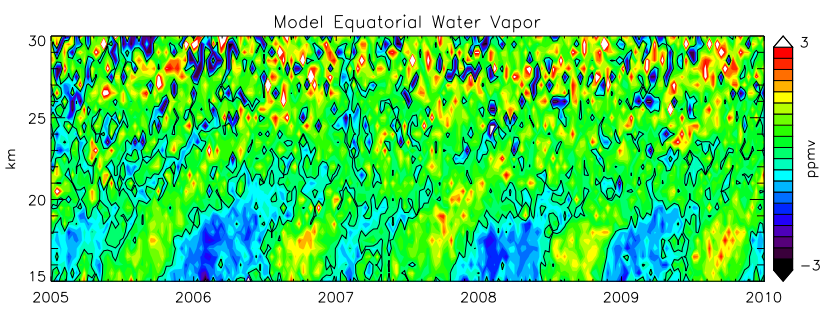

(b)

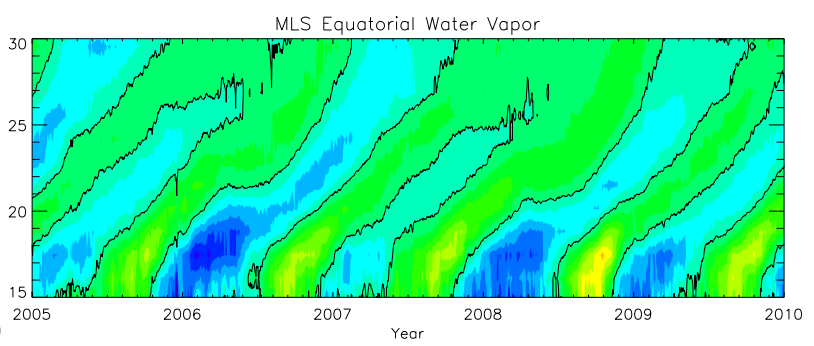

(c)

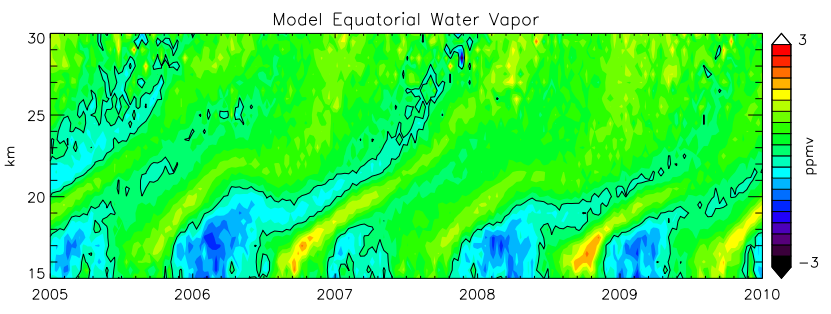

Fig. 7. Water vapor concentration anomalies at the equator $\left( \pm 1^{\circ}\right)$ vs. time. (a) K120 (kinematic) experiment, (b) MLS V3 observations. Missing MLS data is interpolated over the gaps. (c) D104 (diabatic) experiment (see Table 1).

abatic experiments the dehydration locations are nearly the same. The point density is obtained in Fig. 8a by counting final dehydration locations in a $5^{\circ} \times 10^{\circ}$ latitude-longitude grid and normalizing by the total number of parcels. The altitudelatitude density pattern shown in Fig. $8 \mathrm{~b}$ is obtained the same way using a $5^{\circ} \times 1.35 \mathrm{~km}$ latitude-height grid.

In agreement with many previous studies, the principle dehydration region is the Tropical West Pacific (TWP), which is the coldest part of the TTL (e.g. Krueger et al., 2008; Fueglistaler et al., 2009, and others). However, outside the TWP, Fig. 8a shows significant dehydration taking place in zones over India, Africa, South America and Antarctica. Somewhat surprising is the wide extent of dehydration over South America although this region of dehydration also appears in the back trajectory studies by Fueglistaler et al. (2005) and Krueger et al. (2008). Very low water vapor amounts are observed by MLS and simulated by the model (Fig. 6a) are consistent with this being a zone of dehydration. It is also interesting that the TWP dehydration region is split into two regions, one north of the equator extending to East Asia, and one south of the equator extending from northern Australia across eastern New Guinea. This TWP dipole dehydration distribution also shows up in the vertical distribution of dehydration locations (Fig. 8b) and reflects the 
(a)

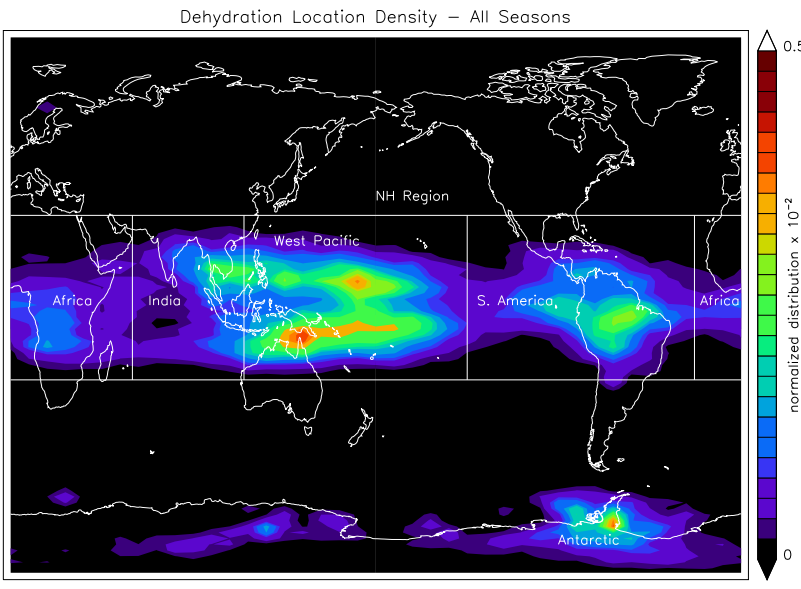

(b)

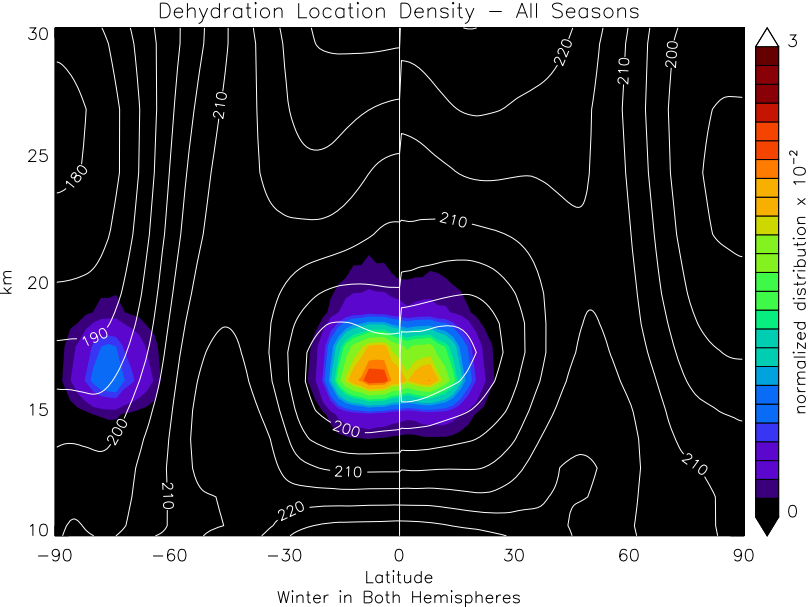

Fig. 8. Upper plot (a) shows horizontal distribution of final dehydration location density for all parcels more than $1 \mathrm{yr}$ old, regardless of when they were dehydrated (from the D100 run). The lower plot (b) shows the annual vertical distribution of dehydration locations along with the winter zonal mean temperature contours superimposed (winter in the $\mathrm{SH}$ and winter in the $\mathrm{NH}$ ).

MERRA temperature fields. To illustrate this, we have overlaid the winter temperatures in Fig. 8b to illustrate the colocation of cold temperatures and final dehydration points in the tropics and over Antarctica.

Figure 9 shows the D100 seasonal distribution of final dehydration density for $\mathrm{NH}$ winter (December-February), spring (March-May), summer (June-August) and fall (September-November). The NH winter dehydration exhibits many of the features of the annual average dehydration (Fig. 8a) with the highest density of dehydration points occurring in the southern branch of the TWP dipole and with almost no contribution from East Asia. Dehydration over South America is also important in this season. In spring, the dehydration focus is in the tropical Pacific and SE Asia. Dehydration in the summer is most common over East Asia, with a smaller contribution from Antarctica. In the case of Antarctica, the major dehydration zone lies close to the

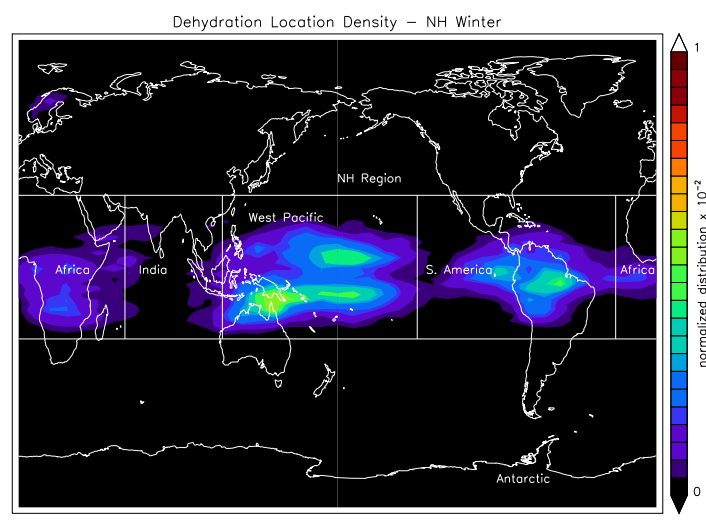

(a)

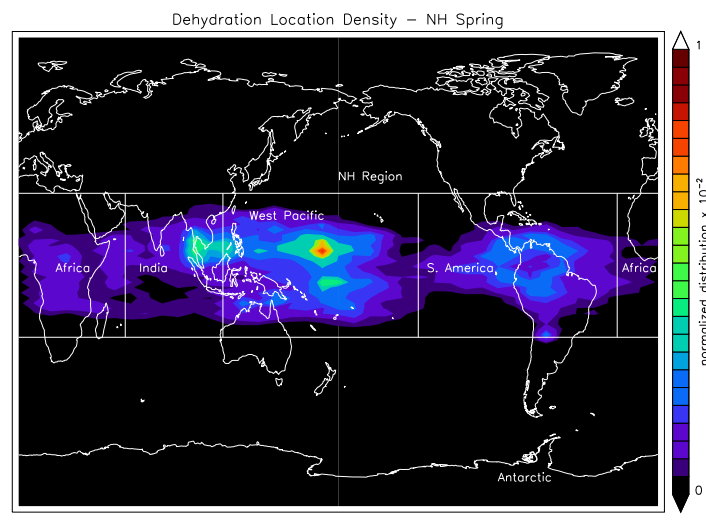

(b)

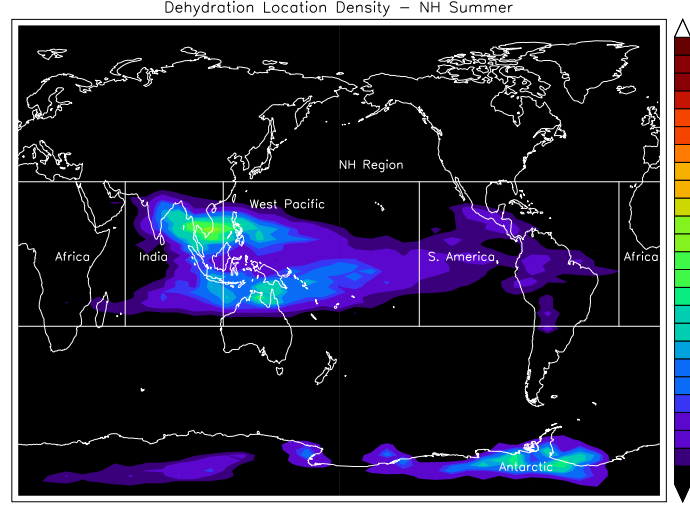

(c)

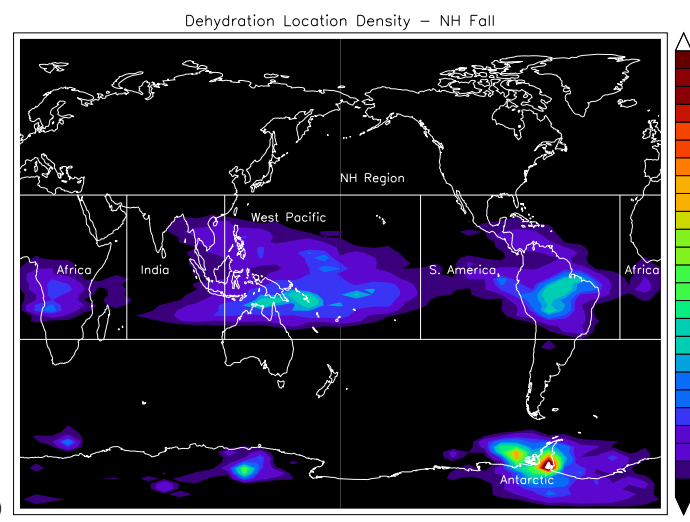

Fig. 9. Density of final dehydration frequency by season. Upper left (a) winter, upper right (b) spring, lower left (c) summer, lower right (d) fall. 
Table 2. Dehydration Statistics by Region.

\begin{tabular}{lcccccc}
\hline Location & \multicolumn{3}{c}{ All Seasons (100\%) } & \multicolumn{2}{c}{ NH Winter (30\%) } & \multicolumn{2}{c}{ NH Summer (24\%) } \\
\hline & $\%$ & $\mathrm{H}_{2} \mathrm{O}$ & $\%$ & $\mathrm{H}_{2} \mathrm{O}$ & $\%$ & $\mathrm{H}_{2} \mathrm{O}$ \\
West Pacific & 41 & 4.2 & 52 & 3.4 & 36 & 5.2 \\
India & 11 & 4.6 & 5 & 3.9 & 20 & 5 \\
South America & 21 & 4.5 & 26 & 3.8 & 10 & 6 \\
Africa & 10 & 4.4 & 15 & 4.1 & 3 & 5.8 \\
Antarctica & 16 & 2.2 & 0 & - & 30 & 2.0 \\
Northern Hemisphere & 1 & 5.8 & $\sim 0$ & - & 1 & - \\
\hline
\end{tabular}

Statistics of final dehydration locations for regions shown in Fig. 8a for the D100 run. Percent shows the total percentage of model parcels that dehydrated in the indicated region. $\mathrm{H}_{2} \mathrm{O}$ is the average water vapor mixing ratio (ppmv) for parcels that dehydrated in that location. Only parcels over a year old are considered.

Antarctic Peninsula where large-scale orographic waves that are resolved by MERRA can depress temperatures. The altitude of this zone is shown in Fig. 8b. North polar gravity wave driven dehydration is also seen in the model, but to a much lesser extent than in the Southern Hemisphere. During NH winter this dehydration mostly occurs over the Scandinavian Peninsula. In the NH fall, dehydration over Antarctica occurs, as does dehydration over S. America and the N. Australia-New Guinea region.

Table 2 shows how each region in Figs. $8 \mathrm{a}$ and 9 contributes to the control of water vapor in the stratosphere in percent and in average water vapor mixing ratio. The percent is of number model parcels (over a year old) that dehydrated in the specified region shown in Fig. 8a map.

As is evident in Figs. 8a and 9 and Table 2, in NH winter the TWP is the predominant locus of dehydration of the stratosphere; however, as noted above, the next most important zone for dehydration is the continent of South America. Water vapor amounts from these zones are about 4 ppmv. In NH summer, dehydration events over India (and east Asia) are most important, but dehydration over Antarctica plays a role as well. During NH summer, the water vapor mixing ratio for parcels that dehydrated over Antarctica average 2 ppmv whereas all other regions the average is $\sim 5-6$ ppmv.

The Antarctic stratosphere reaches minimum temperatures during a period when the polar vortex is very isolated (Schoeberl and Hartmann, 1991) and thus the dry air inside the vortex cannot easily circulate into the Southern Hemisphere until the vortex breaks up in November. Therefore, despite very dry air being produced inside the Antarctic vortex, the net contribution of Antarctica to stratospheric dehydration is still smaller than the overall contribution from the tropics.

Tracking parcels after final dehydration and sorting their distribution as a function of altitude and latitude allows us to further explore the role of the various dehydration zones in controlling stratospheric water vapor. Using the parcel positions, we can show the relative distribution of parcels that have dehydrated in different regions. Figure 10 amplifies the results from Table 2 by showing the instantaneous distribution of parcels on a particular day that dehydrated in each re- gion - we refer to these fractional maps as "Influence". For example, the instantaneous distribution of parcels that had Antarctica as their final dehydration point is the "Antarctic Influence". We neglect the Northern Hemisphere Influence since it is negligible in all seasons and we lump South America and Africa together.

Table 2 and Fig. 10 shows that the TWP influence dominates the stratosphere but that South America and Africa together are important regions for dehydration in NH winter. During the NH summer the influence of the TWP is still higher than India (and East Asia) despite the fact that the water vapor maximum is clearly located over India (Fig. 6b). Note the tape recorder signal moving upward in the tropics as a variation in the dehydration locations. Figure 10b shows that, during Antarctic winter, the vortex confines the dehydration to regions south of $\sim 60^{\circ} \mathrm{S}$. After the breakup of the vortex (early $\mathrm{NH}$ winter), the influence of Antarctic appears to be reduced to the region below $18 \mathrm{~km}$ (Fig. 10a) where a weak vortex persists. Despite the strong dehydration in the Antarctic stratosphere, the overall influence is small. As a side note, the kinematic integrations show much wider influence of the Antarctic region in the Southern Hemisphere (not shown). This wider Antarctic influence in the kinematic model occurs because diffusive parcel exchange across the vortex wall allows more air to be processed by the cold Antarctic stratosphere.

\section{Summary and conclusion}

This paper describes initial results from a domain filling, forward trajectory model that has been developed to examine the dehydration processes that control stratospheric water vapor. We use the MERRA assimilated winds and temperatures in these calculations. Comparing diabatic and kinematic trajectories, we find that the kinematic trajectory results are significantly different from the diabatic calculations. Despite vertical velocity time-smoothing of the MERRA data, the additional stochastic transport due to the vertical velocity "noise" in the kinematic calculation creates too dry a 

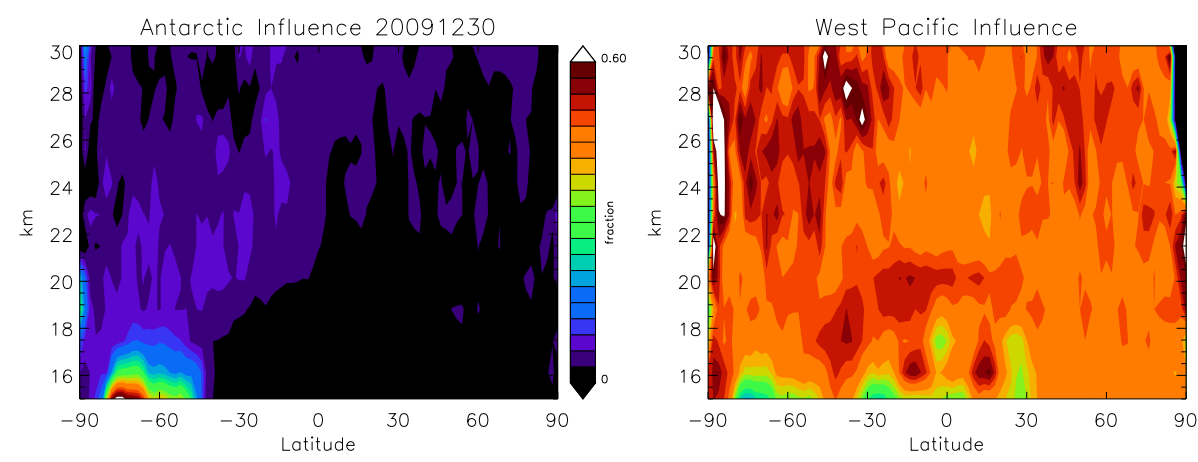

India Influence
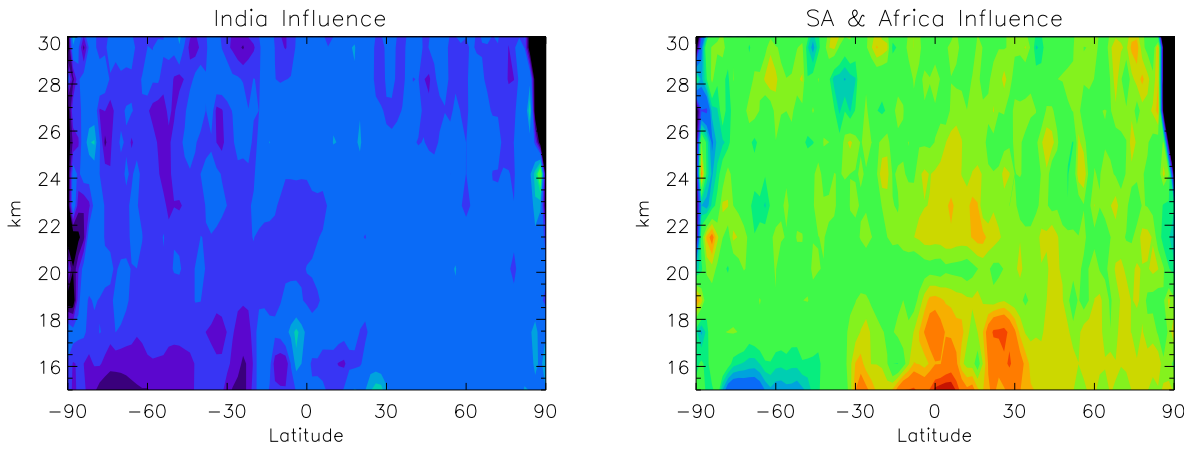

(a)

Antarctic Influence 20090703
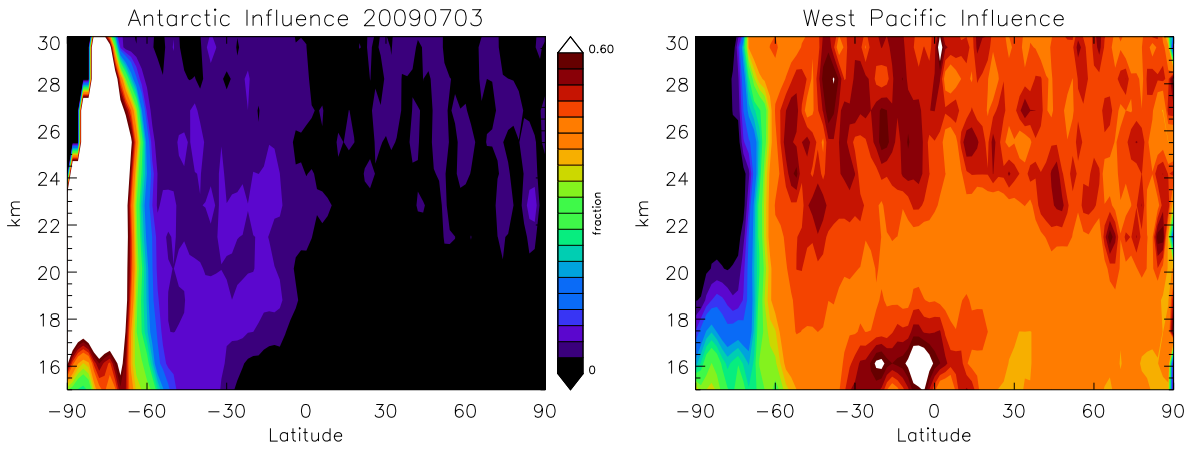

India Influence
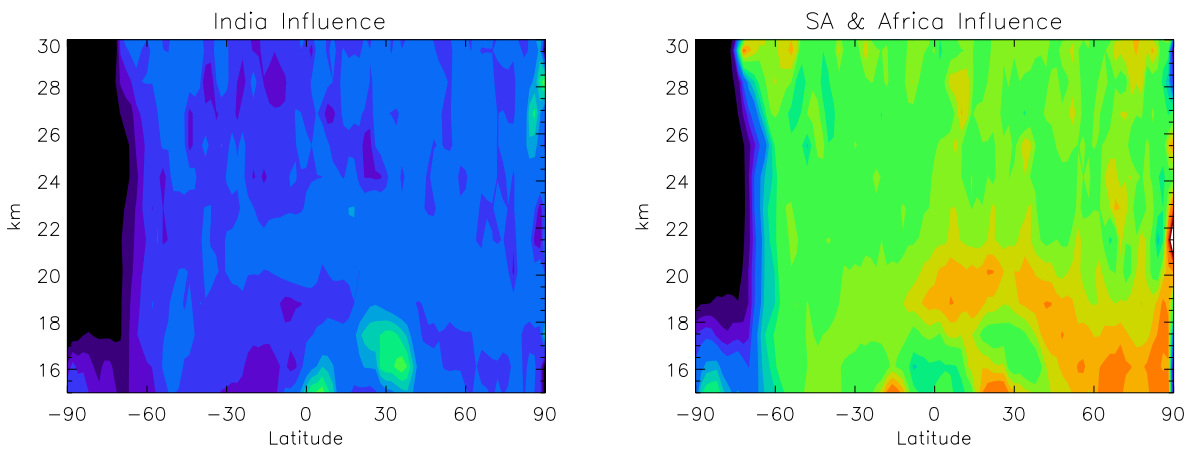

Fig. 10. Gridded instantaneous fractional distribution of parcels that dehydrated in different locations for 31 December 2009 (a) and 3 July 2009 (b), D100, or influence. Figure 8a shows the region map labels.

stratosphere and a too diffuse a tape recorder signal compared observations. The reason the kinematic stratosphere is too dry is because the dispersion of parcels provides a higher probability for encountering cold temperatures and dehydrating.
The diabatic calculations provide more reasonable transport, and the mean age for the diabatic calculation better matches to the observations. Comparisons to MLS water vapor data show that the diabatic simulation of stratospheric water vapor, assuming dehydration at ice saturation, is only 
slightly dry, and the water vapor tape recorder signal compares well to MLS observations although the ascent of the tape signal is too slow. The slight dry bias is consistent with the cold bias in MERRA tropical temperatures at $100 \mathrm{hPa}$.

We explore the effects of changing the super-saturation threshold and including convective moistening and gravity wave induced temperature fluctuations. We can match the MLS observations if we assume super-saturation of about $104 \%$. Alternatively, we can obtain the same agreement with MLS measurements if we include both convective moistening and gravity waves, setting the saturation at $100 \%$. Convective moistening increases stratospheric water vapor and gravity wave temperature fluctuations reduce it. Thus, if we believe that convective moistening must be present to reproduce HDO measurements, (Moyer et al., 1996; Keith, 2000; Dessler et al., 2007) then gravity waves are also required to provide additional dehydration. Future simulations will focus on simultaneously matching $\mathrm{H}_{2} \mathrm{O}$ and HDO stratospheric observations.

The model allows us to quantify the spatial pattern of final dehydration locations. Although we find that the TWP dominates the dehydration processes in winter, South America is also important, and the dry region over South America shows up in the MLS $\mathrm{H}_{2} \mathrm{O}$ observations as well. Antarctica makes an additional contribution to the Southern Hemisphere water vapor budget by releasing very dry air into the Southern Hemisphere stratosphere following the break up of the winter vortex, but its influence is not great. The India-East Asia region is important for dehydration during $\mathrm{NH}$ summer, but it is not as important as TWP.

Acknowledgements. A. Dessler acknowledges NASA Aura grant NNX08AR27G to Texas A\&M University. We thank K. Bowman for help on the trajectory code, and S. Fueglistaler for a helpful review.

\section{Edited by: A. Geer}

\section{References}

Alcala, C. M. and Dessler, A. E.: Observations of deep convection in the tropics using the TRMM precipitation radar, J. Geophys. Res., 107, 4792, doi:10.129/2002JD002457, 2002.

Bosilovich, M. G., Chen, J., Robertson, F. R., and Adler, R. F.: Evaluation of global precipitation in reanalyses. J. Appl. Meteor. Climatol., 47, 2279-2299, doi:10.1175/2008JAMC1921.1, 2008.

Bowman, K. P.: Large-scale isentropic mixing properties of the Antarctic polar vortex from analyzed winds, J. Geophys. Res., 98, 23013-23027, 1993.

Bowman, K. P. and Carrie, G. D.: The mean-meridional transport circulation of the troposphere in an idealized GCM, J. Atmos. Sci., 59, 1502-1514, 2002.

Brewer, A. W.: Evidence for a world circulation provided by the measurements of helium and water vapour distribution in the stratosphere, Q. J. Roy. Meteorol. Soc., 75, 351-363, 1949.
Danielsen, E. F.: Trajectories - isobaric, isentropic and actual, J. Meteorol., 479-486, 1961.

Corti, T., et al.: Unprecedented evidence for deep convection hydrating the tropical stratosphere, Geophys. Res. Lett., 35, L10810, doi:10.1029/2008g1033641, 2008.

Dessler, A. E.: The effect of deep, tropical convection on the tropical tropopause layer, J. Geophys. Res., 107, 4033, doi:10.1029/2001JD000511, 2002.

Dessler, A. E., Weinstock, E. M., Hintsa, E. J., Anderson, J. G., Webster, C. R., May, R. D., Elkins, J. W., and Dutton, G. S.: An examination of the total hydrogen budget of the lower stratosphere, Geophys. Res. Lett., 21, 2563-2566, 1994.

Dessler, A. E., Hintsa, E. J., Weinstock, E. M., Anderson, J. G., and Chan, K. R.: Mechanisms controlling water vapor in the lower stratosphere: "A tale of two stratospheres", J. Geophys. Res., 100, 23167-23172, 1995.

Dessler, A. E., Palm, S. P., and Spinhirne, J. D.: Tropical cloud-top height distributions revealed by the Ice, Cloud, and Land Elevation Satellite (ICESat)/Geoscience Laser Altimeter System (GLAS), J. Geophys. Res., 111, D12215, doi:10.1029/2005JD006705, 2006.

Dessler, A. E., Hanisco, T. F., and Fueglistaler, S. A.: Effects of convective ice lofting on $\mathrm{H}_{2} \mathrm{O}$ and $\mathrm{HDO}$ in the tropical tropopause layer, J. Geophys. Res., 112, D18309, doi:10.1029/2007JD008609, 2007.

Fleming, E. L., Jackman, C. H., Weisenstein, D. K., and Ko, M. K. W.: The impact of inter-annual variability on multidecadal total ozone simulations, J. Geophys. Res., 112, D10310, doi:10.1029/2006JD007953, 2007.

Fueglistaler, S., Bonazzola, M., Haynes, P. H., and Peter, T.: Stratospheric water vapor predicted from the Lagrangian temperature history of air entering the stratosphere in the tropics, J. Geophys. Res., 110, D08107, doi:10.1029/2004JD005516, 2005.

Fueglistaler, S., Dessler, A. E., Dunkerton, T. J., Folkins, I., Fu, Q., and Mote, P. W.: The tropical tropopause layer, Rev. Geophys., 47, RG1004, doi:10.1029/2008RG000267, 2009.

Gettelman, A. and de F. Forster, P. M.: A climatology of the tropical tropopause layer, J. Meteorol. Soc. Jpn., 80, 911-942, 2002.

Gettelman, A., Randel, W. J., Wu, F., and Massie, S. T.: Transport of water vapor in the tropical tropopause layer, Geophys. Res. Lett., 29(1), 1009, doi:10.1029/2001GL013818, 2002.

Gettelman, A. et al.: Multimodel assessment of the upper troposphere and lower stratosphere: Tropics and global trends, J. Geophys. Res., 115, D00M08, doi:10.1029/2009JD013638, 2010.

Hanisco, T., Moyer, E. J., Weinstock, E. M., St. Clair, J. M., Sayres, D. S., Smith, J. B., Lockwood, R., Anderson, J. G., Dessler, A. E., Keutsch, F. N., Spakman, J. R., Read, W. G., and Bui, T. P: Observations of deep convective influence on stratospheric water vapor and its isotopic composition, Geophys. Res Lett., 34, L04814, doi:10.1029/2006GL027899, 2007.

Jensen, E. J. and Pfister, L.: Transport and freeze-drying in the tropical tropopause layer, J. Geophys. Res., 109, D02207, doi:10.1029/2003JD004022, 2004.

Jensen, E. J., Smith, J. B., Pfister, L., Pittman, J. V., Weinstock, E. M., Sayres, D. S., Herman, R. L., Troy, R. F., Rosenlof, K., Thompson, T. L., Fridlind, A. M., Hudson, P. K., Cziczo, D. J., Heymsfield, A. J., Schmitt, C., and Wilson, J. C.: Ice supersaturations exceeding $100 \%$ at the cold tropical tropopause: implications for cirrus formation and dehydration, Atmos. Chem. Phys., 
5, 851-862, doi:10.5194/acp-5-851-2005, 2005.

Jensen, E. J., Ackerman, A. S., and Smith, J. A.: Can overshooting convection dehydrate the tropical tropopause layer?, J. Geophys. Res., 112, D11209, doi:10.1029/2006JD007943, 2007.

Johnson, D. G., Jucks, K. W., Traub, W. A., and Chance, K. V.: Isotopic composition of stratospheric water vapor: Implications for transport, J. Geophys. Res., 106, 12219-12226, 2001.

Keith, D. W.: Stratosphere-Troposphere exchange: Inferences from the isotopic composition of water vapor, J. Geophys. Res., 105, 15167-15173, 2000.

Krüger, K., Tegtmeier, S., and Rex, M.: Long-term climatology of air mass transport through the Tropical Tropopause Layer (TTL) during NH winter, Atmos. Chem. Phys., 8, 813-823, doi:10.5194/acp-8-813-2008, 2008.

Lambert, A., Read, W. G., Livesey, N. J., Santee, M. L., Manney, G. L., Froidevaux, L., Wu, D. L., Schwartz, M. J., Pumphrey, H. C., Jimenez, C., Nedoluha, G. E., Cofield, R. E., Cuddy, D. T., Daffer, W. H., Drouin, B. J., Fuller, R. A., Jarnot, R. F., Knosp, B. W., Pickett, H. M., Perun, V. S., Snyder, W. V., Stek, P. C., Thurstans, R. P., Wagner, P. A., Waters, J. W., Jucks, K. W., Toon, G. C., Stachnik, R. A., Bernath, P. F., Boone, C. D., Walker, K. A., Urban, J., Murtagh, D., Elkins, J. W., and Atlas E.: Validation of the Aura Microwave Limb Sounder middle atmosphere water vapor and nitrous oxide measurements, J. Geophys. Res., 112, D24S36, doi:10.1029/2007JD008724, 2007.

Le Texier, H., Solomon, S., and Garcia, R. R.: The role of molecular hydrogen and methane oxidation in the water vapor budget of the stratosphere, Q. J. Roy. Meteorol. Soc., 114, 281-296, doi:10.1002/qj.49711448002, 1988.

Liebmann, B. and Smith, C. A.: Description of a complete (interpolated) outgoing longwave radiation data set, B. Am. Meteorol. Soc., 77, 1275-1277, 1996.

Liu, Y. S., Fueglistaler, S., and Haynes, P.: Advection-condensation paradigm for stratospheric water vapor, J. Geophysical Res., 115, D24307, doi:10.1029/2010JD014352, 2010.

Marti, J. and Mauersberger, K.: A survey and new measurements of ice vapor pressure at temperatures between $170 \mathrm{~K}$ and $250 \mathrm{~K}$, Geophys. Res. Lett., 20, 363-366, 1993.

Mote, P. W., Rosenlof, K. H., McIntyre, M. E., Carr, E. S., Gille, J. C., Holton, J. R., Kinnersley, J. S., Pumphrey, H. C., Russell III, J. M., and Waters, J. W.: An atmospheric tape recorder: The imprint of tropical tropopause temperatures on stratospheric water vapor, J. Geophys. Res., 101, 3989-4006, 1996.

Moyer, E. J., Irion, F. W., Yung, Y. L., and Gunson, M. R.: ATMOS stratospheric deuterated water and implications for tropospherestratosphere transport, Geophys. Res. Lett., 23, 2385-2388, 1996.

Murphy, D. M. and Koop, T.: Review of the vapour pressures of ice and supercooled water for atmospheric applications, Q. J. Roy. Meteorol. Soc., 131, 1539-1565, 2005

Ploeger, F., Konopka, P., Gunther, G., Grooß, J.-U., and Muller, R.: Impact of the vertical velocity scheme on modeling transport in the tropical tropopause layer, J. Geophys. Res., 115, D03301, doi:10.1029/2009JD012023, 2010.

Plumb, R. A.: Stratospheric Transport, J. Meteor. Soc. Jpn., 80, 793-809, 2002.

Read, W. G., Lambert, A., Backmeister, J., Cofield, R. E., Christensen, L. E., Cuddy, D. T., Daffer, W. H., Drouin, B. J., Fetzer, E., Froidevaux, L., Fuller, R., Herman, R., Jarnot, R. F., Jiang,
J. H., Jiang, Y. B., Kelly, K., Knosp, B. W., Pumphrey, H. C., Rosenlof, K. H., Sabounchi, X., Santee, M. L., Schwartz, M. J., Snyder, W. V., Stek, P. C., Su, H., Takacs, L. L., Thurstans, R. P., Vomel, H., Wagner, P. A., Waters, J. W., Webster, C. R., Weinstock, E. M., and Wu, D. L.: Aura Microwave Limb Sounder upper tropospheric and lower stratospheric $\mathrm{H}_{2} \mathrm{O}$ and relative humidity with respect to ice validation, J. Geophys. Res. 112, D24S35, doi:10.1029/2007JD008752, 2007.

Rienecker, M. M., Suarez, M. J., Gelaro, R., Todling, R., Bacmeister, J., Liu, E., Bosilovich, M. G., Schubert, S. D., Takacs, L., Kim, G.-K., Bloom, S., Chen, J., Collins, D., Conaty, A., Da Silva, A., Gu, W., Joiner, J., Koster, R. D., Lucchesi, R., Molod, A., Owens, T., Pawson, S., Pegion, P., Redder, C. R., Reichle, R., Robertson, F. R., Ruddick, A. G,. Sienkiewicz, M., and Woollen, J.: NASA's Modern-Era Retrospective Analysis for Research and Applications, J. Climate, 24, 3624-3648, doi:10.1175/JCLI-D11-00015.1, 2011.

Rosenlof, K. H. and Reid, G. C.: Trends in the temperature and water vapor content of the tropical lower stratosphere: Sea surface connection, J. Geophys. Res., 113, D06107, doi:10.1029/2007JD009109, 2008.

Rosenlof, K. H., Oltmans, S. J., Kley, D., Russell III, J. M., Chiou, E.-W., Chu, W. P., Johnson, D. G., Kelly, K. K., Michelsen, H. A., Nedoluha, G. E., Remsberg, E. E., Toon, G. C., and McCormick, M. P.: Stratospheric water vapor increases over the past half-century, Geophys. Res. Lett., 28, 1195-1198, 2001.

Schiller, C., Grooß, J.-U., Konopka, P., Plöger, F., Silva dos Santos, F. H., and Spelten, N.: Hydration and dehydration at the tropical tropopause, Atmos. Chem. Phys., 9, 9647-9660, doi:10.5194/acp-9-9647-2009, 2009.

Schoeberl, M. R. and Hartmann, D.: The Dynamics of the Polar Vortex, Science, 251, 46-52, 1991.

Schoeberl, M. R. and Sparling, L.: Trajectory Modeling, in: Diagnostic Tools in Atmospheric Physics, G. Fiocco and G. Visconti eds., Proceedings of the International School of Physics "Enrico Fermi", 124, 289-306, 1995.

Schoeberl, M., Douglass A., Zhu Z., and Pawson S.: A comparison of the lower stratospheric age spectra derived from a general circulation model and two data assimilation systems, J. Geophys. Res., 108(D3), 4113, doi:10.1029/2002JD002652, 2003.

Schoeberl, M. R., Douglass, A. R., Newman, P. A., Lait, L. R., Lary, D., Waters, J., Livesey, N., Froidevaux, L., Lambert, A., Read, W., Filipiak, M. J., and Pumphrey, H. C.: QBO and annual cycle variations in tropical lower stratosphere trace gases from HALOE and Aura MLS observations, J. Geophys. Res., 113, D05301, doi:10.1029/2007jd008678, 2008a.

Schoeberl, M. R., Douglass, A. R., Stolarski, R. S., Pawson, S., Strahan, S. E., and Read, W.: Comparison of lower stratospheric tropical mean vertical velocities, J. Geophys. Res, 113, D24109, doi:10.1029/2008JD010221, 2008b.

Sherwood, S. C. and Dessler, A. E.: On the control of stratospheric humidity, Geophys. Res. Lett., 27, 2513-2516, 2000.

Steinwagner, J., Fueglistaler, S., Stiller, G. P., von Clarmann, T., Kiefer, M., Borsboom, P.-P., van Delden, A., Röckmann, T.: Tropical dehydration processes constrained by the seasonality of stratospheric deuterated water, Nat. Geosci., 3, 262-266, 2010.

Waugh, D. W. and Hall, T. M.: Age of stratospheric air: Theory, observations, and models, Rev. Geophys., 40(4), 1010, doi:10.1029/2000RG000101, 2002. 
Wofsy, S. C., McConnell, J. C., and McElroy, M. B.: Atmospheric $\mathrm{CH}_{4}, \mathrm{CO}$, and $\mathrm{CO}_{2}$, J. Geophys. Res., 77, 4477-4493, 1972.

Wrotny, J. E., Nedoluha, G. E., Boone, C., Stiller, G. P., and McCormack, J. P.: Total hydrogen budget of the equatorial upper stratosphere, J. Geophys. Res., 115, D04302, doi:10.1029/2009JD012135, 2010,
Zhou, X. L., Geller, M. A., and Zhang, M. H.: Cooling trend of the tropical cold point tropopause temperatures and its implications, J. Geophys. Res., 106, 1511-1522, 2001.

Zipser, E. J., Cecil, D. J., Liu, C., Nesbitt, S. W., and Yorty, D. P.: Where are the most intense thunderstorms on Earth?, B. Am. Meteorol. Soc., 87, 1057-1071, 2006. 